\title{
REVISIÓN TEÓRICA DE LA ENFERMEDAD DEL TINNITUS Y ANÁLISIS Y PROCESAMIENTO DE LAS SEÑALES PROCEDENTES DEL OÍDO MEDIANTE matlab, Adobe Audition y Spectra Plus
}

\author{
Jesús Llanos-Ávila ${ }^{1}$
}

${ }^{1}$ Docente de tiempo completo, de la Facultad de Ingeniería, Universidad Cooperativa de Colombia, sede Bogotá Correos-e: jllanosav@gmail.com, jesus.llanos@correoucc.edu.co

Recibido: 20 de diciembre del 2012. Aprobado: 10 de febrero del 2013.

Cómo citar este artículo: J. Llanos-Ávila, "Revisión teórica de la enfermedad del tinnitus y análisis y procesamiento de las señales procedentes del oído mediante MATLAB, Adobe Audition y Spectra Plus”. Ingeniería Solidaria, Vol. 9, №. 16, pp. 65-79, Dic., 2013.

Resumen. En este documento se presenta la realización de un análisis de señales procedentes del oído en pacientes con acúfenos, para establecer una posible relación con las otoemisiones acústicas espontáneas presentes en la mayoría de los oídos normales. Previo a este análisis se realiza una revisión teórica de las otoemisiones acústicas, estableciendo las clases y las aplicaciones en la clínica médica para la determinación objetiva de alteraciones de la audición tomando como base una exhaustiva y cuidadosa selección de artículos científicos hecha con el fin de presentar una contextualización pertinente, adecuada y concisa. Las señales adquiridas y posteriormente analizadas corresponden a un grupo de cinco pacientes voluntarios con padecimiento de acúfeno. El artículo es producto de la investigación "Desarrollo de un equipo instrumento diagnóstico para la determinación objetiva del tinnitus", del grupo de investigación en “Tinitus” del Hospital La Samaritana. Esta investigación viene desarrollándose desde el 2006.

Palabras clave: acúfenos, análisis, otoemisiones acústicas, señales, tinnitus.

Theoretical Review of TinNitus and ANalysis of the Processing of Signals Generated by the Ear Using matlab, Adobe Audition y Spectra Plus

Abstract. This paper presents the analysis of signals emitted by the ears of patients suffering tinnitus, to establish a possible link with spontaneous otoacoustic emissions that are present in most normal ears. Prior to this analysis, a theoretical review was conducted of otoacoustic emissions, establishing the classes and applications in clinical practice to objectively determine hearing impairment. The basis for this was a set of articles with important scientific content, arrived at through an exhaustive selection process in order to provide a relevant, adequate and concise context. The signals captured and later analyzed correspond to a group of five volunteer patients who suffer from tinnitus. This article is a product of the research study titled "Developing diagnostic equipment to objectively determine tinnitus", conducted by the "Tinnitus" research group at the La Samaritana hospital. This research has been ongoing since 2006.

Keywords: otoacoustic emissions, analysis, signals, tinnitus.

\begin{abstract}
REVISÃo TEÓRICA DA DOENÇA DE TINNITUS E ANÁLISE E PROCESSAMENTO DOS SINAIS PROCEDENTES DO OUVIDO mediante matlab, Adobe Audition e Spectra Plus
\end{abstract}

Resumo. Neste documento, apresenta-se a realização de uma análise de sinais procedentes do ouvido em pacientes com acufenos, para estabelecer uma possível relação com as otoemissões acústicas espontâneas presentes na maioria dos ouvidos normais. Previamente a esta análise, realiza-se uma revisão teórica das otoemissões acústicas, ao estabelecer os tipos e aplicações na clínica médica para a determinação objetiva de alterações da audição que tomou como base uma escolha de artigos de grande conteúdo científico para os quais se teve um processo de seleção exaustivo com o objetivo de apresentar uma contextualização pertinente, adequada e concisa. Os sinais adquiridos e posteriormente analisados correspondem a um grupo de cinco pacientes voluntários com padecimento de acufeno. O artigo é produto da pesquisa "Desenvolvimento de um equipamento instrumento diagnóstico para a determinação objetiva do tinnitus", do grupo de pesquisa em "Tinnitus" do Hospital La Samaritana. Esta pesquisa vem desenvolvendo-se desde 2006.

Palavras-chave: acufenos, análise, otoemissões acústicas, sinais, tinnitus. 


\section{Introducción}

\subsection{Otoemisiones acústicas}

La evidencia de que la cóclea, además de recibir y analizar los sonidos, es capaz de producir energía acústica de una forma activa fue demostrada por David Kemp en 1978 [1]. Esta capacidad coclear fue predicha por Gold en 1948, quien determinó que para alcanzar el nivel de discriminación subjetivo que posee el oído humano es necesario un elevado valor " $Q$ " de resonancia de la membrana basilar, para lo cual sería necesario la existencia de algún proceso activo que anulara la amortiguación de esta membrana por los líquidos cocleares con producción de emisiones sonoras por parte de la cóclea como consecuencia de algún producto lateral de este proceso [2]. Esta teoría fue inicialmente rechazada y cayó en el olvido. Kemp retomó estas ideas y comprobó la existencia de estas emisiones en humanos, las registró tras la estimulación de la cócleacon un estímulo tipo click con un micrófono implantado en el CAE (conducto auditivo externo), tras un periodo de latencia entre 5-15 msg. Posteriormente, se confirmó su existencia en animales de experimentación como ratones, ratas, cerdos de Guinea, chinchilla, conejos, perros y monos $[3,4]$.

Múltiples trabajos de investigación han confirmado la existencia de estas otoemisiones acústicas, su origen biológico y más concretamente su origen en las CCE (células ciliadas externas). Se ha relacionado su existencia con una función auditiva normal, expresando un buen funcionamiento de los mecanismos cocleares activos (elementos fundamentales en la audición de sonidos de escasa intensidad). Por lo tanto, la existencia de este fenómeno en inicio controvertido, fue finalmente aceptado por la comunidad científica internacional, definiéndose la otoemisión acústica como la fracción de sonido generada por la actividad fisiológica de la cóclea que puede ser registrada en el CAE [5].

La importancia de este descubrimiento radica en que a través del estudio de las otoemisiones acústicas disponemos de un método de evaluación objetivo del feedback de la mecánica coclear por el que las CCE (células ciliadas externas) y las fibras del sistema eferente son responsables de las curvas de sintonía y de discriminación frecuencial asociadas a la audición normal [6]. Los oídos sanos, como vimos, emplean las contracciones activas de las CCE para intensificar la sensibilidad a un sonido, generándose en este proceso una energía sonora retrógra- da que se transmite hacia el oído externo en forma de otoemisión acústica. Una vez confirmada la existencia de estas emisiones y su importancia en el campo de la investigación audiológica básica, los esfuerzos se dirigieron a simplificar los sistemas de registros experimentales existentes en los distintos laboratorios de investigación, con el fin de obtener los registros de una forma rápida y sencilla [7-9]. Tras varios años de investigación en el Instituto de Laringología y Otología de Londres, se diseñó el analizador otodinámico ILO 88 para el registro de otoemisiones acústicas [10-12]. Desde la aparición del primer equipo en 1988, el ILO 88, hasta hace poco tiempo la mayoría de los trabajos de investigación básica fueron realizados con este instrumental y los resultados se podían comparar sin dificultad. Pero en la actualidad, debido a la incorporación de otros equipos al mercado, ha obligado a establecer pautas que permitan comparar los resultados, debido a que no existen normas de orden internacional IsO o ANSI para uniformar los equipos.

Existen varios objetivos médicos que podrían ser alcanzados con el uso de OAE (otoacoustic emission-emisiones otoacústicas). Lo primero es el tamizaje auditivo o también llamado screening [13] para detectar pérdidas auditivas en poblaciones de neonatos y niños, aunque en el futuro se espera que el screening no se limite a detectar exclusivamente pérdidas auditivas. Otros autores han examinado a pacientes con síndrome de Meniere y determinaron que las OAE pueden proveer información diagnóstica útil [14]. Harris, Probst y Wegner han explorado las relaciones entre OAE y daños debido a medicamentos ototóxicos y exposiciones al ruido [15]. Pero los anteriores logros médicos son sólo una pequeña porción del potencial de investigación de las OAE, y tal como lo señala Lonsbury [16], las OAE continúan siendo de gran interés para los investigadores; por esta razón, las aplicaciones clínicas que permiten las OAE están destinadas a prosperar con el paso de tiempo.

\subsection{Origen}

En sus trabajos iniciales, Kemp [1] ya establece el posible origen coclear de las OAE al definir a estas como la energía acústica generada tras estimulación sonora, presumiblemente por la motilidad activa generada dentro de las CCE. Tras la confirmación de la existencia del fenómeno físico de la emisión acústica en humanos, animales de experimentación e incluso en modelos analógicos computarizados, su origen biológico queda confirmado por una serie de hechos: 
- Las características acústicas dinámicas de las otoemisiones acústicas provocadas por estímulos transitorios indican que estas tienen su origen en un sistema no lineal, ya que la progresión de la respuesta a medida que se incrementa la intensidad del estímulo no sigue un crecimiento lineal, alcanzándose la saturación a partir de una intensidad determinada [1]. Este comportamiento no lineal es característico de los sistemas biológicos.

- Las teoAe (Transient evoked otoacoustic emissions) se presentan con una latencia mayor de lo que un ecofísico produciría $[3,4]$.

- Cuando se detectan teoAe en animales de experimentación, estas desaparecen tras la muerte del animal [17].

Como ya se ha mencionado anteriormente, desde un principio se consideró que el sistema biológico no lineal en el que se originan las OAE era la cóclea, al ser este un órgano en el que se encuentra una serie de estructuras susceptibles de activarse mecánicamente, luego de la estimulación sonora y con capacidad de producir energía acústica tras esta activación. Se han realizado múltiples trabajos experimentales con el fin de confirmar el origen coclear de las OAE, existiendo en la actualidad gran cantidad de argumentos a favor de este origen:

- Es posible generar OAE en modelos analógico-digitales computarizados que reproducen las condiciones del oído interno [18].

- En humanos, las OAE están ausentes en todos aquellos casos en los que existe patología coclear [19].

- En animales de experimentación, desaparecen o disminuyen las OAE cuando determinados agentes provocan alteración de la función coclear [20].

- Las teoAe están presentes entre el 96 y el 100\% de sujetos con audición normal [21], y desaparecen en todos aquellos casos de patología coclear que provocan pérdidas auditivas superiores a $35 \mathrm{~dB}$ [22-25].

- Todos los tipos de oAe sufren reducciones de la amplitud tras traumas acústicos, cuando se producen elevaciones temporales del umbral (TTS), tras estímulos sonoros se produce una disminución de la amplitud de la TEOAE [25]. En animales de experimentación se verifica la existencia de este mismo fenómeno luego de la inducción de lesiones cocleares localizadas, producidas por estímulos sonoros con especificidad frecuencial.
- Las oAE se pueden modificar con ruidos de enmascaramiento [26].

- La amplitud de la TEOAE puede ser reducida por un sonido de frecuencia vecina a la frecuencia de la emisión, siendo este fenómeno especialmente identificable en las otoemisones acústicas espontáneas.

- El empleo de fármacos ototóxicos, como los aminoglucósidos o la furosemida, provoca la desaparición de las OAE [27].

- La ingesta de altas dosis de ácido acetilsalicílico produce aboliciones reversibles de las OAE [28], siendo las otoemisones acústicas espontáneas más sensibles a estos fármacos al desaparecer con menores dosis y tardar más tiempo en reaparecer.

- Existe una relación clara entre la latencia de las ondas y la frecuencia de la OAE, de forma que las emisiones con frecuencias más elevadas poseen una latencia más corta [28]. Este hecho guarda relación con la codificación de las frecuencias agudas en las espiras más basales de la cóclea.

- En aquellos casos en los que existe una alteración de la transmisión de los sonidos a través del oído medio no se registran otoemisiones. Este efecto es reversible cuando se subsana la alteración que dificultaba la transmisión directa de la onda del estímulo y la inversa de la emisión [29].

Todos estos argumentos están a favor del origen coclear de las OAE. Como hemos visto, en la fisiología coclear y a raíz del conocimiento más íntimo de los mecanismos activos cocleares, las CCE destacan como el posible lugar de origen de ellas; progresivamente, una serie de hallazgos han ido definiendo las CCE como el lugar de origen de las OAE:

- Se han registrado OAE procedentes de cultivos de CCE en cavidades tras estimulaciones con sonidos [30].

- Las CCE se anclan por sus dos polos entre la membrana basilar y la membrana tectoria, de lo cual resulta una capacidad de transducción de la energía mecánica o eléctrica de forma bidireccional, siendo las OAE un subproducto de este fenómeno, transmitido de forma retrógrada [30].

- En animales de experimentación la presencia o ausencia de otoemisiones acústicas está en función de la existencia de CCE. Las cepas de ratones mutantes w/w que sólo poseen CCI no generan OAE; en cambio, en las cepas homocigóticas Bronx Waltzer, que sólo poseen CCE, sí se registran, a pesar de existir una hipoacusia de percepción con ausencia de potencial 
de acción y reducción del potencial microfónico coclear [30]. Los ratones de afness, por el contrario, no tienen CCE y tampoco otoemisiónacústica, hecho que respalda el papel de las CCE.

- Las teoAe presentan un comportamiento no lineal similar al que presentan las contracciones de las CCE in vivo.

- La administración de ototóxicos que lesionan selectivamente las CCE provocan hipoacusia y desaparición de las OAE [31].

- La desaparición temporal de las OAE, tras la administración de altas dosis de ácido acetilsalicílico, estaría en relación con la pérdida del turgor celular de las CCE.

- Las CCE establecen la mayoría de sus contactos sinápticos con las fibras del sistema eferente medial. Se ha comprobado la existencia de un efecto modulador de la mecánica coclear después de la activación de este sistema que puede ser objetivado a través de las variaciones que se producen en la amplitud de las TEOAE, tras la estimulación acústica contralateral [31].

- Los umbrales visuales de detección de teOAE son menores que el umbral psicoacústico de percepción del click, lo cual apoya el origen preneural de las emisiones [20].

Como resultados de todas estas experiencias, en la actualidad se considera que las OAE tienen su origen en la actividad contráctil de las CCE, expresando su existencia la integridad de la función mecánica de la membrana basilar y de estas células. Las OAE serían un reflejo de la existencia de los mecanismos activos derivados de la contracción de las CCE, que amplifican la vibración de la membrana basilar y modulan la excitación de las CCI. El resultado de este fenómeno es la propiedad de la discriminación frecuencial fina que posee la cóclea humana - audición de sonidos de intensidad débil, selectividad frecuencial. Las células ciliadas externas parecen ser las células fundamentalmente responsables del origen de la gran selectividad frecuencial, se han establecido correlaciones entre las modificaciones anatómicas observadas en las células ciliadas y las modificaciones funcionales, en concreto la selectividad frecuencial utilizando para ello la inyección de la peroxidasa de rábano en las fibras auditivas de ratones, en los que se han realizado destrucciones localizadas de las CCE por traumatismos sonoros [32]. En esta contracción activa de las CCE se originarían las OAE como un epifenómeno en forma de una onda sonora que se propagaría a lo largo de la membrana basilar en senti- do inverso a la onda de Békésy, y posteriormente a través de la cadena de huesecillos y la membrana timpánica hasta alcanzar el CAE, donde puede ser registrado.

\section{Tipos de otoemisiones acústicas}

Podemos clasificar las otoemisiones acústicas según el tipo de estímulo aplicado para evocar su aparición.

\subsection{Otoemisiones acústicas espontáneas (SOAE)}

Son señales acústicas de aproximadamente $20 \mathrm{~dB}$ SPL, claramente por encima del nivel de ruido del sistema registradas en ausencia de estímulo sonoro. Aparecen como una señal de banda estrecha con uno o varios picos frecuenciales entre 0,5 y $6,0 \mathrm{kHz}$, aunque más frecuentemente entre 1,0 y $2,0 \mathrm{kHz}$. Su existencia implica normoacusia en frecuencias próximas a la SOAE, ya que es necesaria una cóclea indemne para su génesis, pero su ausencia no se relaciona con hipoacusia. Diversos estudios han tratado de establecer su prevalencia en la población infantil y en la de adultos. Así, Spoendlin [30] referencia que Lamprecht-Dinessen las encontraron en el $90 \%$ de los neonatos mujeres y en el $73 \%$ de los varones; a los seis años de edad la prevalencia había descendido al $77 \%$ en niñas y al $68 \%$ en los niños. En adultos, las estadísticas son muy variables, pero en general rondan el 30 y el 40\%, según estudios [25-29]. En otros trabajos, la prevalencia es del $43 \%$ y atribuye las diferencias entre los estudios a la distinta sensibilidad de los equipos [30].

\subsection{Otoemisiones acusticas provocadas (OAEP)}

Son las generadas por la aplicación de un determinado estímulo:

- Otoemisiones acústicas provocadas por estímulos transitorios (TEOAE): las otoemisiones acústicas provocadas son las señales acústicas originadas en la cóclea tras la estimulación de ésta con cliks o tonos Burst [30], es decir, provocadas por un estímulo breve, tal como un click o tonos Burst (trenes de ondas a una frecuencia seleccionada).

- Otoemisiones acústicas provocadas por estímulo frecuencial (SFOAE): provocadas por un tono puro, continuo y de bajo nivel, tienen poco interés en la práctica por la dificultad del registro y análisis de la 
respuesta. Durante la estimulación con tonos puros continuos, la energía en el canal auditivo incluye tanto el estímulo de incidencia, el sonido reflejado desde la membrana timpánica y el sonido que refleja la energía proveniente desde la cóclea. Lo que aporta la cóclea es una versión del estímulo que aparece con un tiempo de demora [30].

- Productos de distorsión acústica (DPOAE): provocados cuando se estimula la cóclea con dos tonos puros de distinta frecuencia (f1 y f2), que se presentan simultáneamente. Las DPOAE son relativamente fáciles de extraer, ya que aparecen en frecuencias que pueden ser predichas exactamente desde las frecuencias de los tonos primarios [30].

De todos los tipos de oAE descritas, las que mayor aplicación tienen en la clínica son las TEOAE y DPOAE, que tienen las siguientes características comunes:

- Son test objetivos rápidos y no invasivos

- Generadas en las CCE

- Elevada sensibilidad ante injurias cocleares

- Presentes en oídos normales con una incidencia del 96-100\%

- Ausentes o reducidas en oídos patológicos

Las características que las diferencian las enumeramos a continuación:

- Los dPoAe tienen una latencia más corta que las TEOAE.

- Aunque tienen un origen común en las CCE, las TEOAE se originarían en la membrana basolateral y los DPOAE en los estereocilios.

- Las TEOAE están ausentes cuando los umbrales de la audiometría tonal limilar (ATL) son iguales o superiores a $30 \mathrm{~dB} \mathrm{HL}$.

- Los DPOAE están ausentes cuando los umbrales de la ATL son iguales o superiores a 45-55 dB HL (144).

- Las teOAe evalúan las frecuencias medias: 1,0-2,0 $\mathrm{kHz}$.

- Las DPOAE estudian un rango frecuencial mayor: $0,5-8,0 \mathrm{kHz}$.

- Mayor selectividad frecuencial de los DPOAE que las TEOAE.

- Las teoAe son mejor método que los dpoAe en el screening neonatal de la audición; diversos autores consideran el registro con TEOAE el método de elección de despistage inicial de las hipoacusias de los re- cién nacidos, siendo complementario del registro con potenciales evocados del tronco cerebral $[10,11]$.

\subsection{Otoemisiones acusticas transitorias (TEOAE)}

LaS TEOAE son el primer tipo de otoemisión registrada por David Kemp en 1977, y por ello también son conocidas como "Ecos de Kemp"; son la evidencia objetiva de la función del mecanismo coclear e implica una función normal del oído. Las TEOAE han sido empleadas en gran escala para el screening auditivo desde hace más de diez años, aunque existen excepciones; la mayoría han usado alguna versión de Otodynamics ILO para los screenigs auditivos.

\section{Características generales}

Las otoemisiones acústicas provocadas por estímulos transitorios son el tipo de otoemisión que inicialmente se desarrolló y que en la actualidad presenta una aplicación clínica importante. Cuando registramos este tipo de OAE, lo que realmente nos importa es determinar la presencia o ausencia de emisión, es decir, determinar si dicho oído es capaz de generar teoae. Para lograr la respuesta de las otoemisiones evocadas transitorias, pueden utilizarse varios tipos de estímulos, de los cuales los clicks y los tonos Burst son los de mayor aplicación. Ambos se caracterizan por ser de corta duración, de ahí el nombre de la respuesta que originan. El click es un ruido de banda ancha en el cual todas las frecuencias incluidas tienen aproximadamente la misma amplitud, este tipo de estímulo es el más utilizado en la práctica clínica y en investigaciones.

Los tonos Burst también es un estímulo muy breve que permite estimular la cóclea con mayores intensidades que los clicks. Se han analizado las respuestas de las TEOAE usando clicks y tonos Burst, concluyendo que para frecuencias altas no hay ventajas en usar tonos Burst, mientras que en frecuencias bajas, $500 \mathrm{~Hz}$, sí se logran emisiones de mayor amplitud que con los clicks [30].

Un aspecto importante es la elección de la intensidad del estímulo, ya que guarda relación con la forma de la onda y con las distintas frecuencias en que estas aparecen. Se sabe que la respuesta es lineal hasta cierta amplitud del estímulo y por encima de este nivel se produce por saturación un comportamiento no lineal, se utilizan estímulos de aproximadamente $80 \mathrm{~dB}$ SPL. 
La cuantificación de la respuesta en forma de amplitud de la TEOAE depende de una gran cantidad de parámetros como la intensidad, el tipo y la frecuencia del estímulo empleado, la función de transferencia del oído medio, las características del análisis espectral de la TEOAE y la técnica de registro empleada. Todo esto hace muy difícil la determinación de unos valores normales que nos permitan la aplicación clínica. El análisis de las curvas de entrada-salida o curvas de intensidad muestran un crecimiento lineal de la amplitud de la TEOAE, a medida que se incrementa la intensidad del estímulo entre 10 y $20 \mathrm{~dB} \mathrm{HL}$, produciéndose la saturación a partir de 30 $\mathrm{dB}$ HL [31]. La existencia de esta saturación constituye una de las características de las OAE que nos permite su identificación.

Respecto al número de clicks que se utilizan por unidad de tiempo, se conoce que cuando aumentan los estímulos por segundo disminuye la amplitud de la otoemisión, lo mismo ocurre si se reduce el intervalo entre clicks de 20 ms a $1 \mathrm{~ms}[30]$.

La aparición de la otoemisión se produce con una latencia determinada respecto al estímulo que provoca su aparición, dependiendo esta latencia de la frecuencia de la emisión. Las OAE de frecuencias graves presentarán una latencia más larga que las de frecuencia más agudas [30]. De esto podemos concluir que las OAE de frecuencias más bajas se generan en regiones más apicales que las de frecuencia más elevada. El estudio de la latencia de las TEOAE es dificultoso debido al encabalgamiento entre la señal multifrecuencial que constituye la TEOAE, y el final de la señal que constituye el estímulo, siendo frecuente la contaminación de la respuesta por la cola del estímulo [31]. A pesar de estas dificultades, la mayoría de estudios establecen que la latencia de las OAE de $1 \mathrm{kHz}$ se sitúa entre 10-16 msg [28-31], siendo este valor superior a la latencia del pico N1 de la electrococleografía, atribuyéndose esta diferencia al tiempo necesario para que se produzca la transmisión reversa de la emisión coclear. Nelly y Norton relacionan la latencia de la emisión con la intensidad del estímulo de forma que la latencia disminuye a medida que se incrementa la intensidad [31]. Debido a las dificultades expuestas, el parámetro latencia posee una escasa aplicación clínica.

El umbral de detección de la TEOAE mediante el análisis visual inferior al umbral psicoacústico de percepción del click, es un aspecto importante para establecer el origen preneural de la TEOAE [30]. Los estímulos de 20-30 dB sPL pueden ser utilizados para establecer si aparece una TEOAE, pudiéndose extrapolar ante su presencia que dicho individuo posee unos umbrales au- ditivos $<30 \mathrm{~dB}$ HL [31]. Esta estimación se refiere al umbral medio de audición en las frecuencias audiométricas de 0,5, 1,0, 2,0 y 4,0 kHz. Los últimos estudios han evidenciado que el umbral para la presencia de TEOAE es aproximadamente a partir 35 a $40 \mathrm{~dB}$. Aunque estas afirmaciones son ciertas para la mayoría de casos clínicos, hay ejemplos en los que las respuestas de TEOAE existen a pesar de observar deterioro del oído. Estos son sobre todo casos donde hay audición residual en 1,0 o 2,0 kHz. En general, las TEOAE no pueden predecir el umbral auditivo debido a que en el proceso de la audición están implicadas más partes del sistema auditivo que la periferia; sin embargo, cuando las funciones del oído externo y medio son normales y no existen complicaciones retrococleares, los resultados audiométricos y los de las TEOAE están en concordancia, cualquier desviación de esto causaría un desacuerdo entre las TEOAE y los resultados audiométricos.

Tras su aparición, las TEOAE presentan una duración que varía entre unos pocos msg hasta varios cientos, siendo este un parámetro que ha permitido diferenciar las TEOAE en dos categorías:

TEOAE de corta duración $(<20 \mathrm{msg})$ y TEOAE de larga duración (>20 msg) (152). Son más frecuentes las TEOAE de larga duración (67-82\%), coincidiendo que en los oídos en los que se registran estas presentan un porcentaje de aparición de SOAE en el 50\% de los casos, en cambio en aquellos oídos en los que existían TEOAE de corta duración no se registraban nunca SOAE $[26,28]$. Esta clasificación de las TEOAE según su duración posee escaso valor clínico y se puede considerar arbitraria, pues está en función del estímulo empleado para evocar la aparición de la emisión, además existen dificultades para diferenciar exactamente el inicio de la otoemisión de la cola del estímulo [11]. La teOAE es una respuesta multifrecuencial compuesta por varias emisiones con distinta latencia, amplitud, duración y umbral que se puede medir en forma de Sound Pressure Level, dB SPL o en intensidades espectrales de la tEOAE [33].

El análisis espectral de una TEOAE muestra que esta es una señal compleja multifrecuencial formada por una serie de picos de banda estrecha [34], lo cual nos sugiere que una OAE provocada por un click está compuesta por una serie de OAE cuyas frecuencias se corresponden con las de unos generadores fijos repartidos a lo largo de la membrana basilar. En estas localizaciones se emitirían estos sonidos de banda estrecha (113), el número de estos picos de banda estrecha varía de 1 a 7 , con una media de 3 , situándose la frecuencia dominante alrededor de $1 \mathrm{kHz}$ [34]. Esta frecuencia dominante aparece sólo 
cuando el estímulo que la provoca contiene dichas frecuencias específicas [26].

El número de picos frecuenciales estará en relación directa con la duración de la TEOAE, siendo característico un mayor número de estos picos en las TEOAE de larga duración, persistiendo algunos de ellos en ausencia de estimulación, los cuales se corresponderían con la presencia de una SOAE [34]. La morfología del espectro de la TEOAE estará en función del número y la sintonización de la emisión en los generadores fijos, distribuidos a la largo de la membrana basilar y de la composición espectral del estímulo que provoca su aparición. La última característica de las TEOAE que vamos a señalar es la estabilidad temporal. Estas son estables en el tiempo [27], siendo esta una característica que nos permite comparar los distintos registros y así, analizando las variaciones interindividuales que se producen a lo largo del tiempo, dispondremos de un método objetivo de monitorización de la audición.

En resumen, una señal acústica generada tras la aplicación de un estímulo click no filtrado de 80 usg, adopta las siguientes características generales:

- Crecimiento no lineal

- Saturación con niveles de estimulación moderados

- Dispersión de frecuencias

- Latencia mayor de la esperada a una resonancia física de la membrana basilar

- Latencia variable en función de la frecuencia de la emisión

- Se puede modificar con enmascaramiento

- Invierte su fase y polaridad cuando se invierte la fase y polaridad del estímulo

- Buena reproductibilidad y estabilidad

- Umbral de aparición menor que el umbral psicoacústico de percepción del click, lo que demuestra que se trata de un fenómeno presináptico.

\section{Características de las TEOAE en adultos}

\subsection{Incidencia}

Las TEOAE están presentes en prácticamente todos los individuos con audición normal, la incidencia de aparición de estas emisiones varía entre el 96 y el $100 \%$ de oídos testados (tabla 1), no apreciándose variaciones en la incidencia de aparición de las TEOAE entre niños $\mathrm{y}$ adultos con audición normal [35-38].
Tabla 1. Incidencia de aparición de las TEOAE

\begin{tabular}{|l|c|c|c|}
\hline \multicolumn{1}{|c|}{ Autores } & $\begin{array}{c}\text { No oídos } \\
\text { testados }\end{array}$ & $\begin{array}{c}\text { No oídos } \\
\text { con TEOAE }\end{array}$ & $\begin{array}{c}\text { \% oídos con } \\
\text { TEOAE }\end{array}$ \\
\hline Kapadia (1997) & 397 & 394 & 99,2 \\
\hline Robinette (1992) & 265 & 265 & 100 \\
\hline Stevens (1988) & 36 & 35 & 97 \\
\hline Kemp (1986) & 150 & 150 & 100 \\
\hline Probst (1987) & 29 & 27 & 96 \\
\hline Bonfils (1988) & 262 & 262 & 100 \\
\hline Grandori (1983) & 23 & 22 & 96 \\
\hline Kemp (1978) & 35 & 35 & 100 \\
\hline
\end{tabular}

Fuente: Spoendlin [30]

Robinette, en un estudio realizado en 265 adultos con edades comprendidas entre 20 y 80 años y cuyos umbrales audiométricos eran $<25 \mathrm{~dB}$ entre 500 y $6000 \mathrm{~Hz}$, concluye que "TEOAE observables" fueron encontradas en todos los oídos normales [37]. De los resultados anteriores se extrae un valor promedio de incidencia de aparición de las teOAE de un 98\% de oídos con audición normal, por lo que quedaría un $2 \%$ de normooyentes en los que no se registrarían TEOAE. Para explicar este fenómeno de etiología no aclarada, se han propuesto varías hipótesis:

- Variaciones anatómicas en oído externo o medio

- Defecto en la técnica de registro, generalmente imposibilidad de un correcto ajuste de la sonda

- Excesivo ruido ambiental o fisiológico

- Incapacidad de un estímulo determinado de evocar la aparición de la OAE en un oído, lo cual se subsanaría variando las características de dicho estímulo.

\section{Metodología}

\subsection{Introducción al análisis de señales acústicas mediante Adobe Audition, MATLAB y Spectra plus}

Para el análisis de las señales se ha recurrido al software especializado para sistemas de audio profesional. En la figura 1 se observa una señal captada en un oído con acúfeno, mostrada en el programa Adobe Audition. 


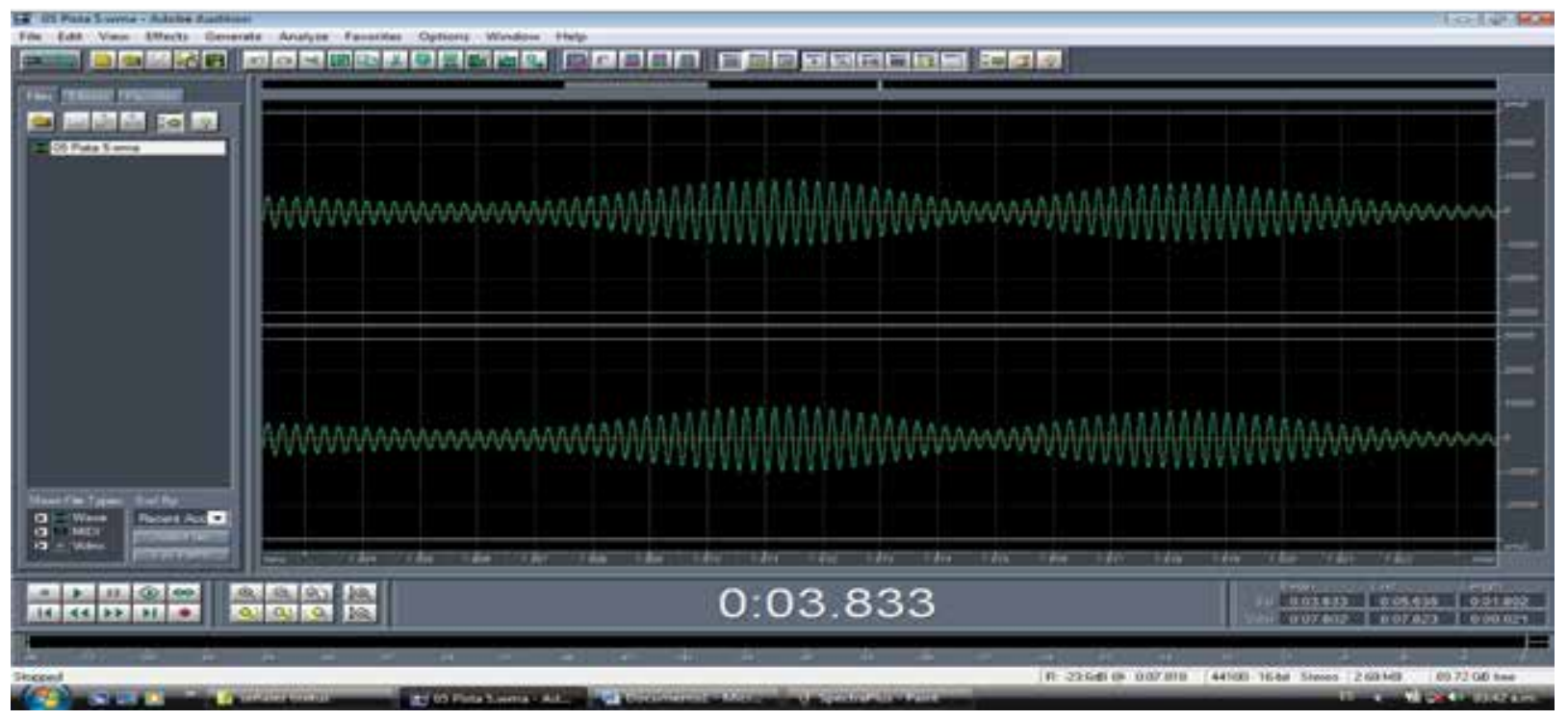

Figura 1. Señal captada en oído de paciente con acúfeno (aspecto de la señal en el dominio del tiempo)

Fuente: los autores

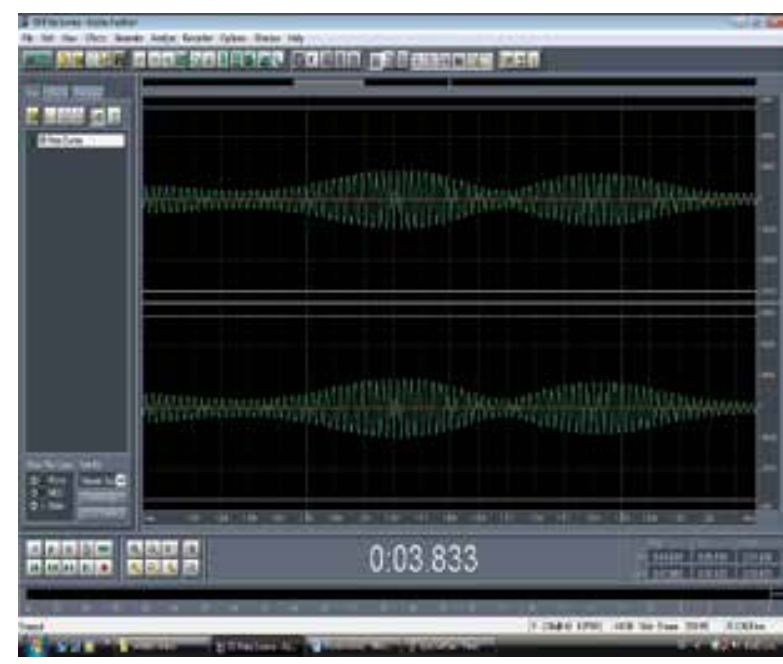

Figura 2. Señal captada en oído de paciente con acúfeno (aspecto de la señal en el dominio del tiempo)

Fuente: los autores

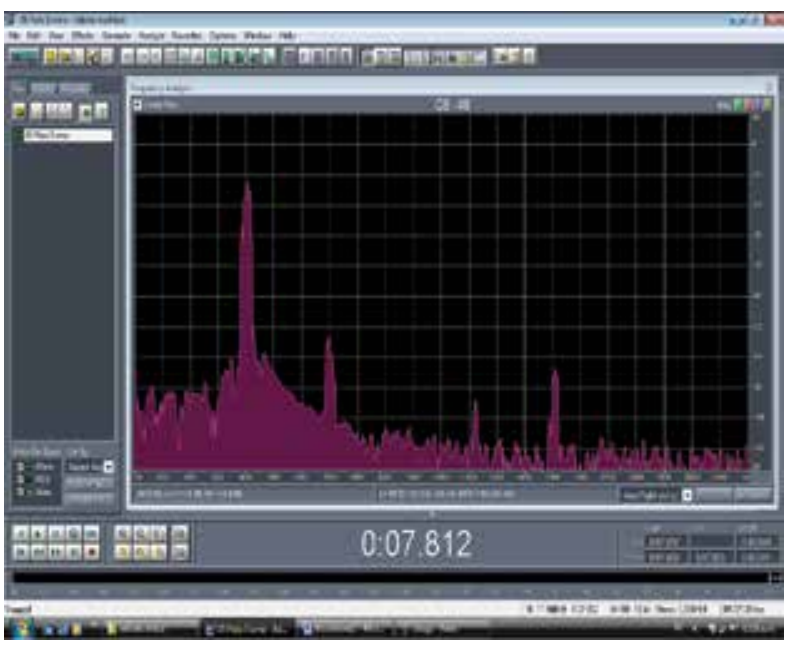

Figura 3. Señal captada en oído de paciente con acúfeno (aspecto de la señal en el dominio de la frecuencia) 
Fuente: los autores

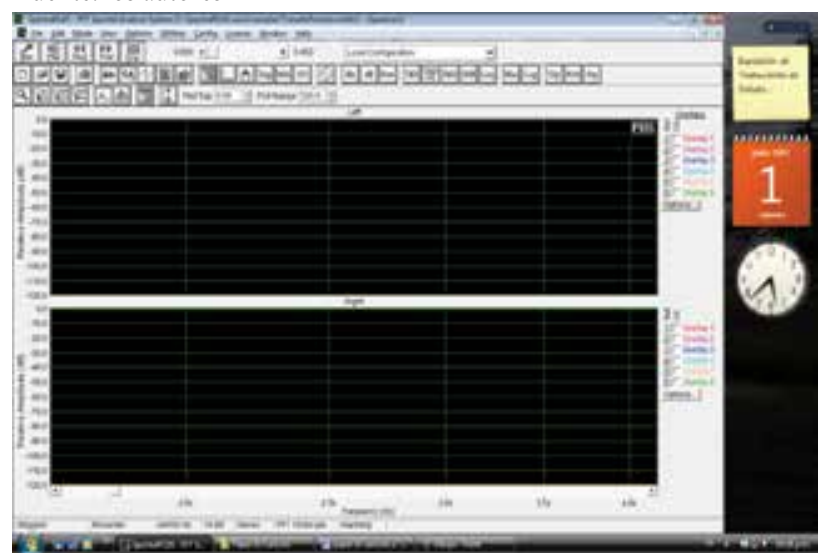

Figura 4. Entorno de trabajo del software Spectra plus (dominio del tiempo)

Fuente: los autores

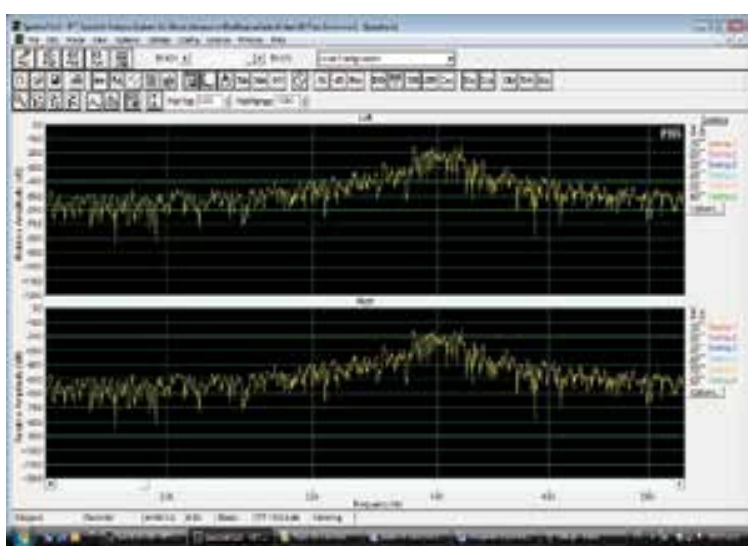

Figura 5. Entorno de trabajo del software Spectra plus (dominio de la frecuencia)

Fuente: los autores

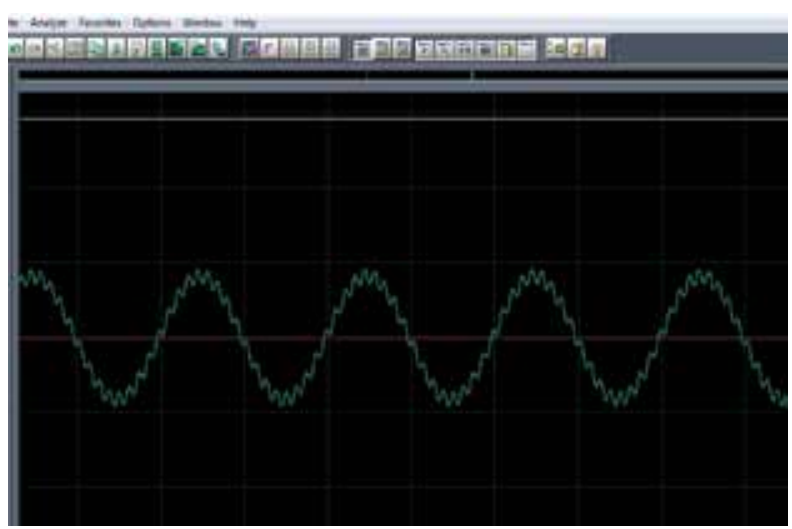

Figura 6. Señal senoidal de $1 \mathrm{kHz}$ con ruido de $17 \mathrm{kHz}$ (aspecto de la señal en el dominio del tiempo)

Fuente: los autores

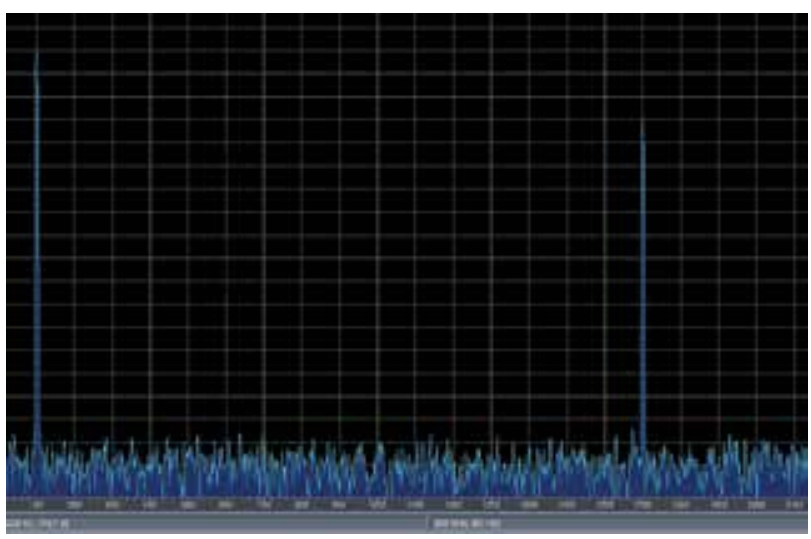

Figura 7. Espectro de la señal de $1 \mathrm{kHz}$ con una señal de ruido de $17 \mathrm{kHz}$

Fuente: los autores

Para el análisis en el dominio de la frecuencia, el software permite trabajar con diferentes tipos de filtros pasa bandas, y el aspecto de cada opción es detallado en las siguientes gráficas extraídas del mismo.

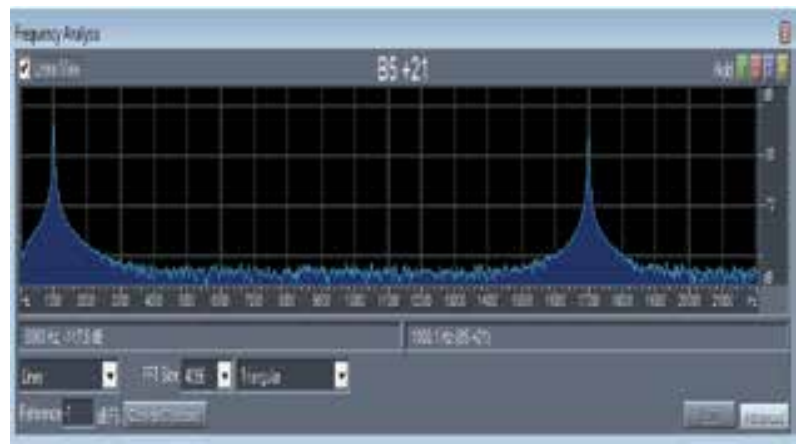

Figura 8. Espectro de la señal de $1 \mathrm{kHz}$ con una señal de ruido de $17 \mathrm{kHz}$ usando filtro de ventana triangular Fuente: los autores



Figura 9. Espectro de la señal de $1 \mathrm{kHz}$ con una señal de ruido de $17 \mathrm{kHz}$, usando filtro de ventana de Hanning Fuente: los autores 


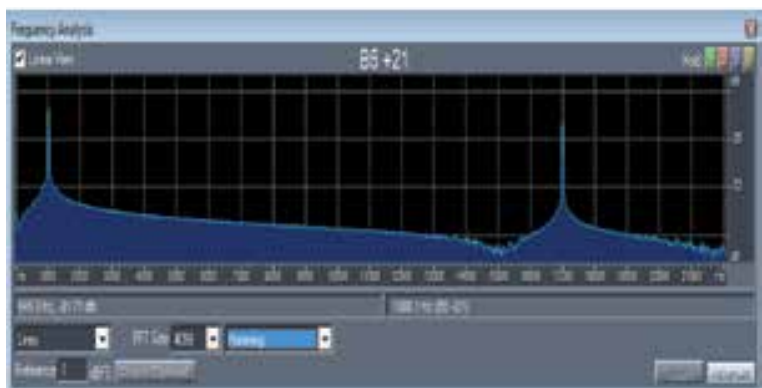

Figura 10. Espectro de la señal de $1 \mathrm{kHz}$ con una señal de ruido de $17 \mathrm{kHz}$, usando filtro de ventana de Hamming.

Fuente: los autores

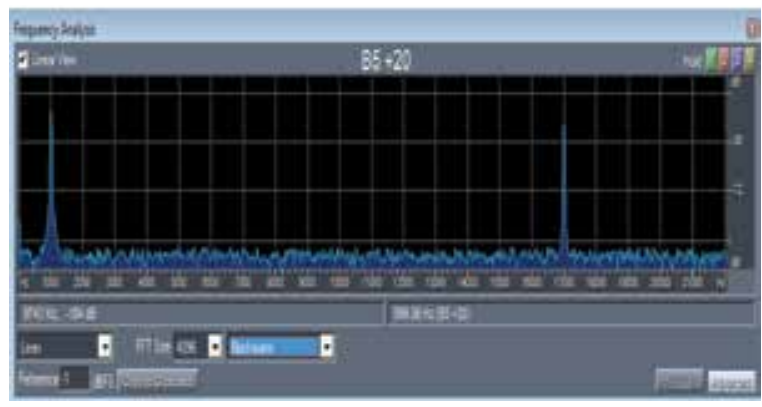

Figura 11. Espectro de la señal de $1 \mathrm{kHz}$ con una señal de ruido de $17 \mathrm{kHz}$, usando filtro de ventana de Blackmann Fuente: los autores

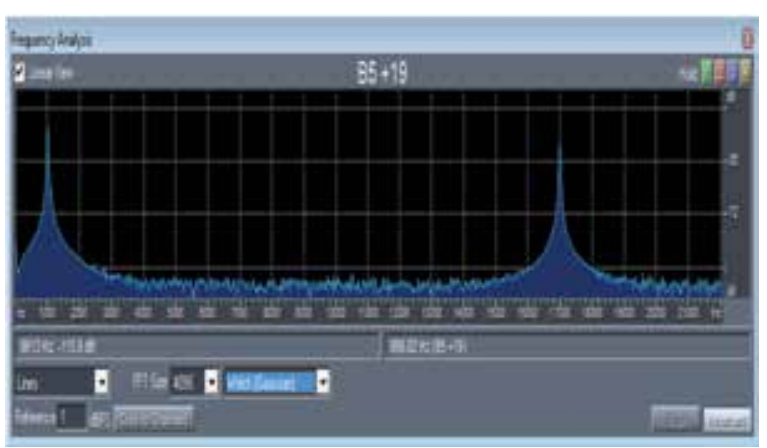

Figura 12. Espectro de la señal de $1 \mathrm{kHz}$ con una señal de ruido de $17 \mathrm{kHz}$, usando filtro de ventana de Welch (Gaussian). Fuente: los autores

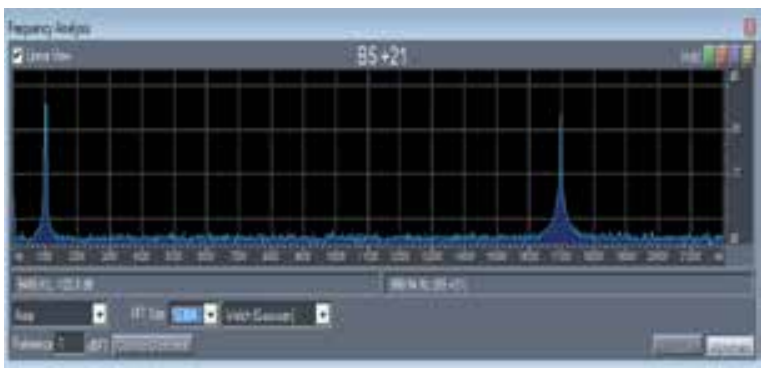

Figura 13. Espectro de la señal de $1 \mathrm{kHz}$ con una señal de ruido de $17 \mathrm{kHz}$ usando filtro de ventana de Welch (Gaussian) con una velocidad de barrido de 4096

Fuente: los autores

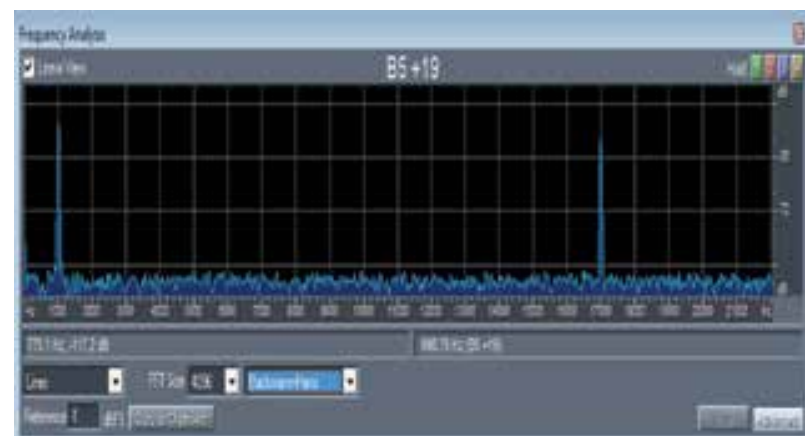

Figura 14. Espectro de la señal de $1 \mathrm{kHz}$ con una señal de ruido de $17 \mathrm{kHz}$ usando filtro de ventana de Blackmann-Harris con una velocidad de barrido de 4096

Fuente: los autores

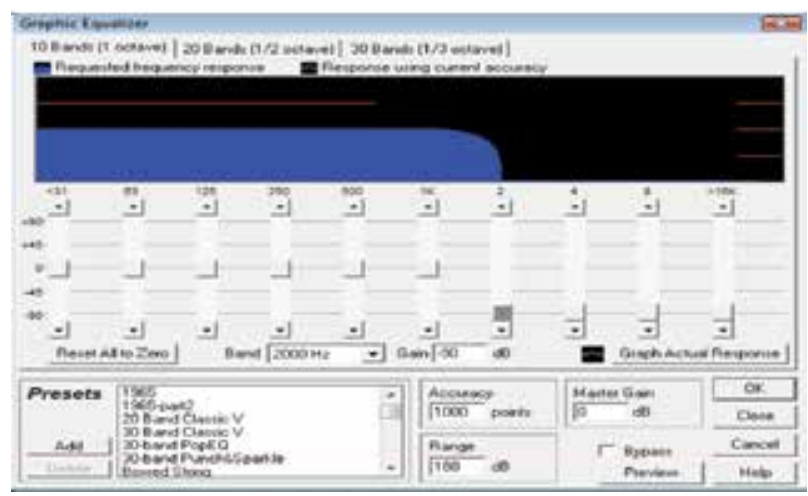

Figura 15. Diseño de filtro pasa bajas para eliminación del ruido de $17 \mathrm{kHz}$

Fuente: los autores

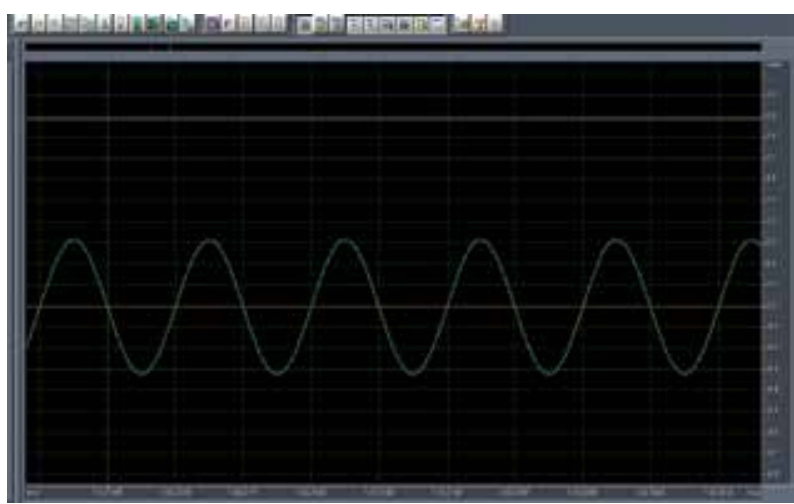

Figura 16. Señal senoidal de $1 \mathrm{kHz}$ filtrada con filtro pasabajos Fuente: los autores 


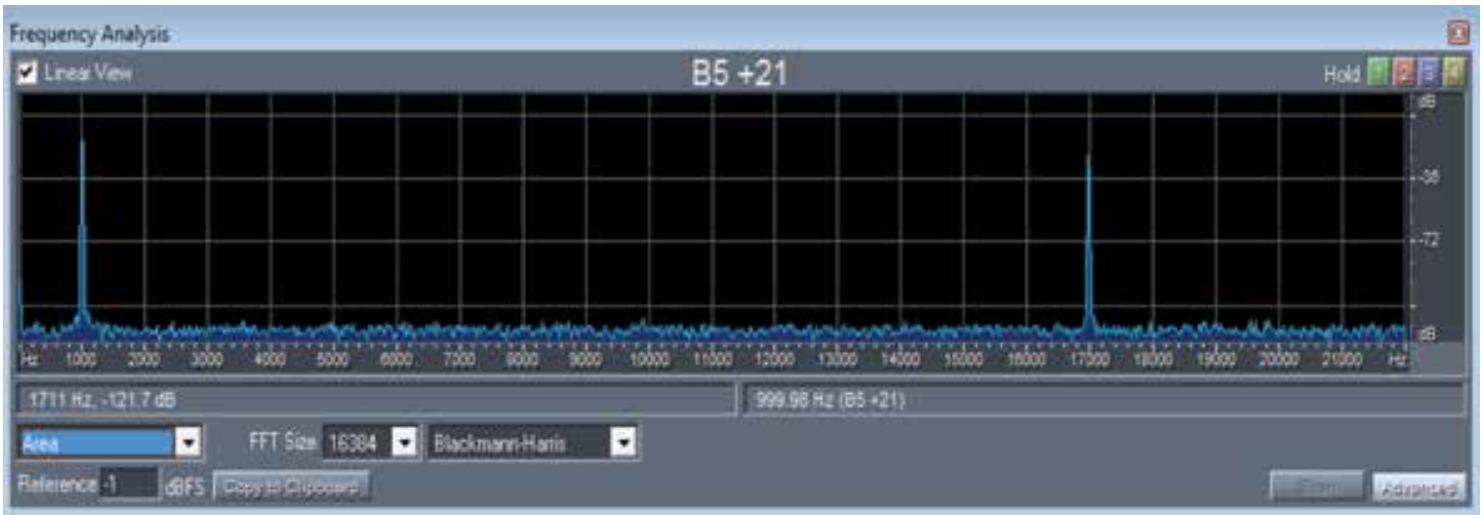

Figura 17. Espectro de la señal de $1 \mathrm{kHz}$ con una señal de ruido de $17 \mathrm{kHz}$, usando filtro de ventana de Welch (Gaussian) Fuente: los autores

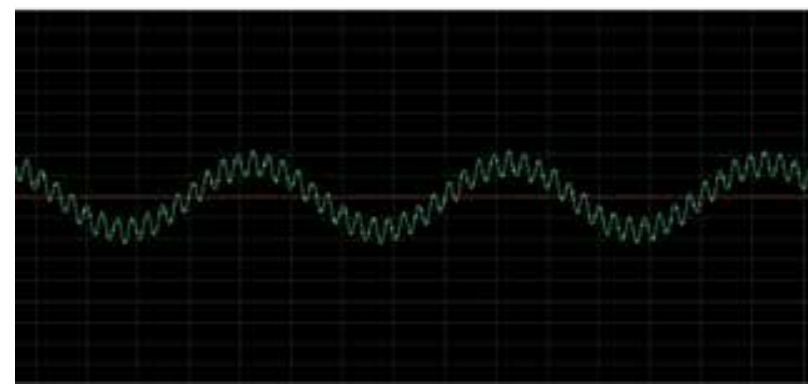

Figura 18. Señal senoidal de $1 \mathrm{kHz}$ con ruido de $17 \mathrm{~Hz}$ (aspecto de la señal en el dominio del tiempo)

Fuente: los autores

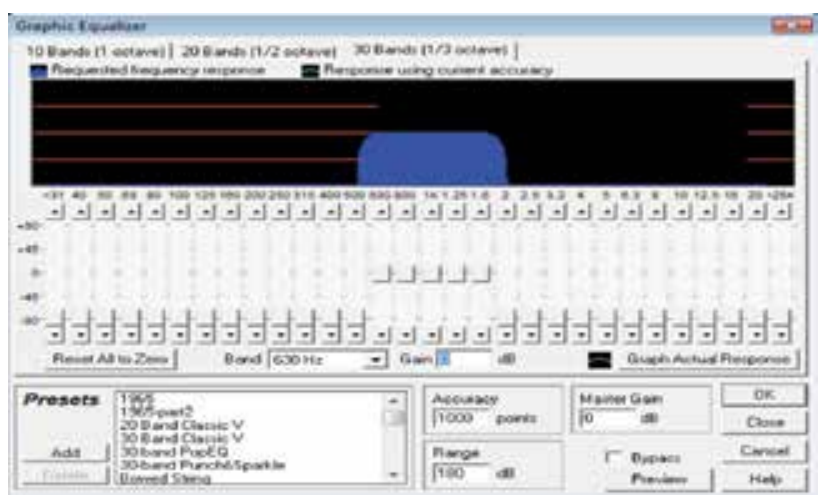

Figura 19. Diseño de filtro pasa banda para supresión del ruido para señal senoidal de $1 \mathrm{kHz}$ con ruido de $17 \mathrm{~Hz}$ con 30 filtros pasa banda (aspecto del filtro en el dominio de la frecuencia) Fuente: los autores

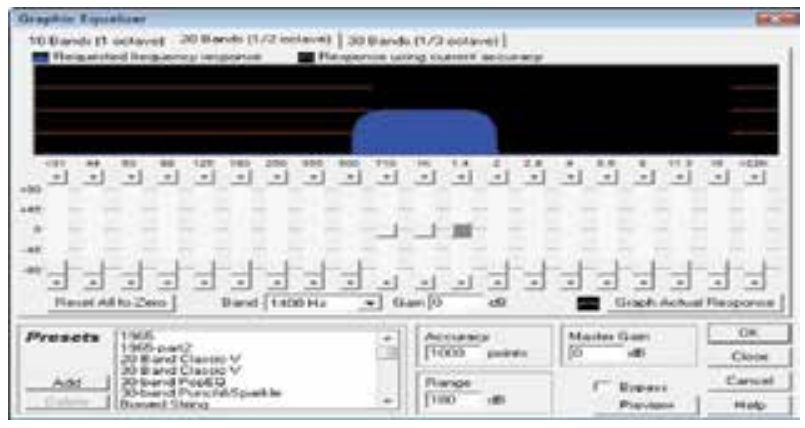

Figura 20. Diseño de filtro pasa banda para supresión del ruido para señal senoidal de $1 \mathrm{kHz}$ con ruido de $17 \mathrm{~Hz}$ con 20 filtros pasa banda (aspecto del filtro en el dominio de la frecuencia) Fuente: los autores

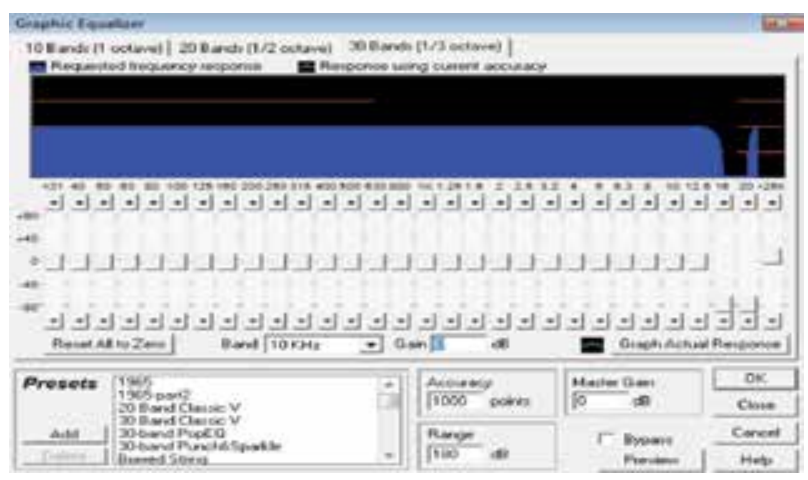

Figura 21. Diseño de filtro supresor de banda para eliminación del ruido para señal senoidal de $1 \mathrm{kHz}$ con ruido de $17 \mathrm{~Hz}$ con 30 filtros pasa banda (aspecto del filtro en el dominio de la frecuencia)

Fuente: los autores 


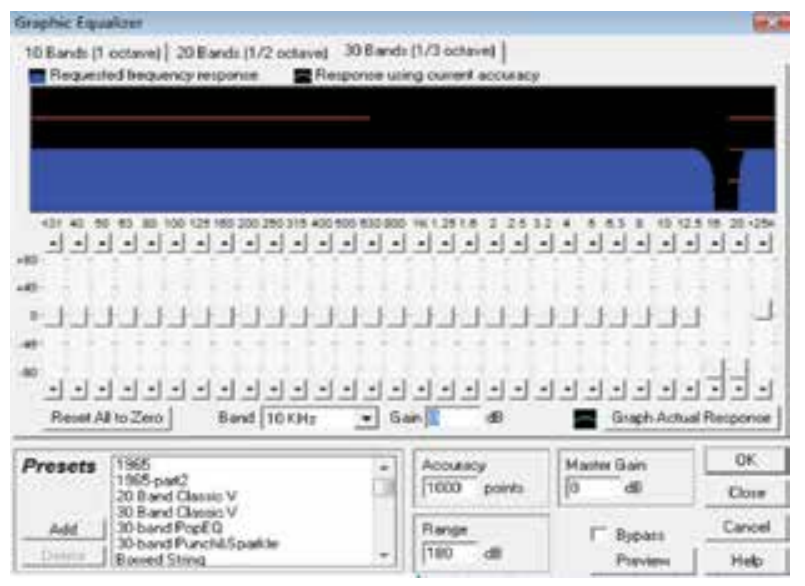

Figura 22. Diseño de filtro supresor de banda para eliminación del ruido para señal senoidal de $1 \mathrm{kHz}$ con ruido de $17 \mathrm{~Hz}$ con 30 filtros pasa banda (aspecto del filtro en el dominio de la frecuencia)

Fuente: los autores

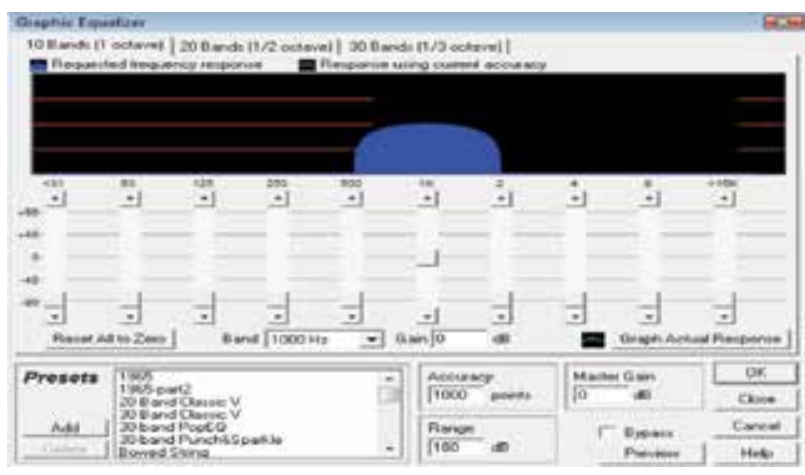

Figura 23. Diseño de filtro pasa banda para supresión del ruido para señal senoidal de $1 \mathrm{kHz}$ con ruido de $17 \mathrm{~Hz}$ con 10 filtros pasa banda (aspecto del filtro en el dominio de la frecuencia) Fuente: los autores

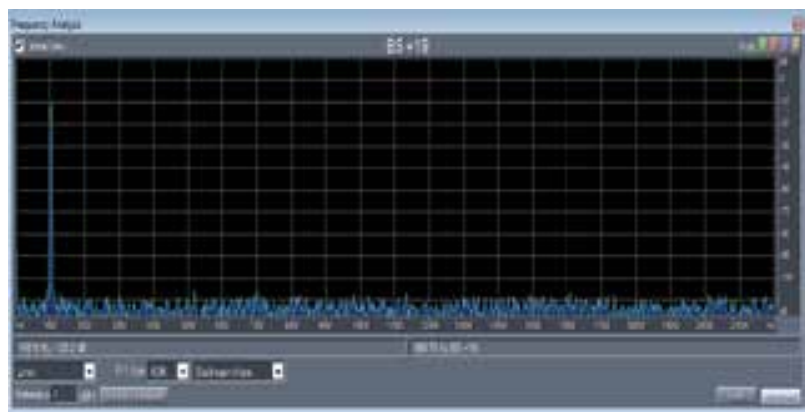

Figura 24. Espectro de la señal de $1 \mathrm{kHz}$ con una señal de ruido de $17 \mathrm{kHz}$, usando filtro de ventana de Welch (Gaussian) Fuente: los autores

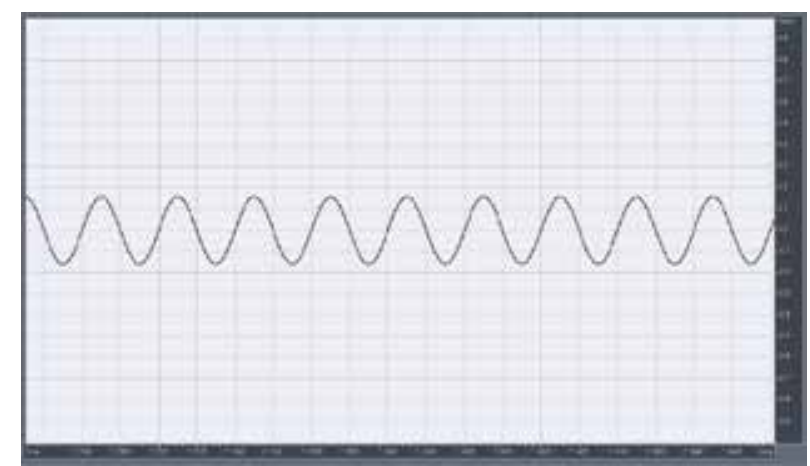

Figura 25. Señal senoidal de $1 \mathrm{kHz}$ filtrada con los filtros anteriores

Fuente: los autores

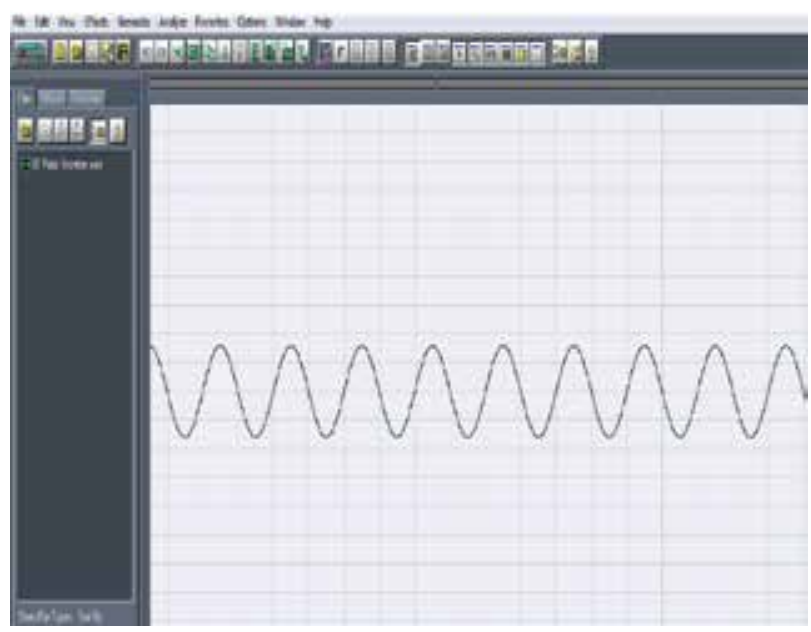

Figura 26. Señal senoidal de $1 \mathrm{kHz}$ filtrada con los filtros anteriores

Fuente: los autores

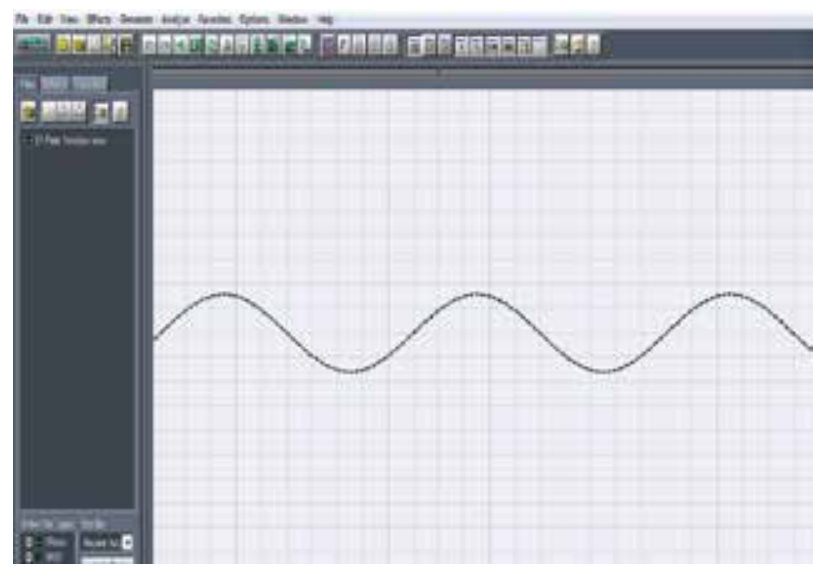

Figura 27. Señal senoidal de $1 \mathrm{kHz}$ filtrada con los filtros anteriores

Fuente: los autores 


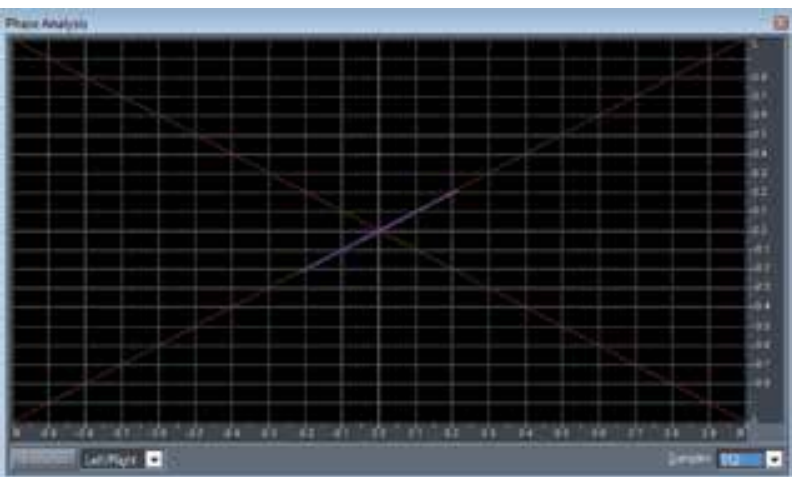

Figura 28. Análisis fasorial de la señal senoidal de $1 \mathrm{kHz}$ filtrada con los filtros anteriores

Fuente: los autores

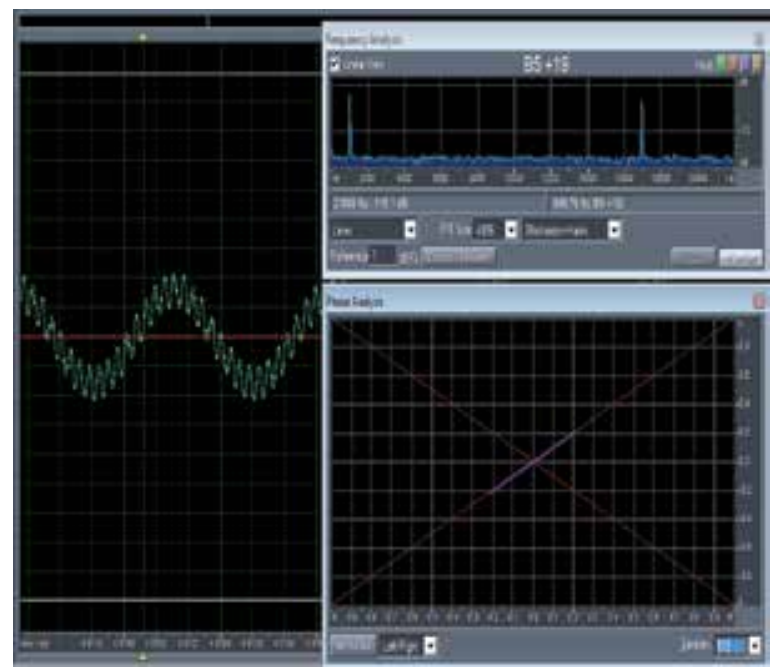

Figura 29. Análisis fasorial de la señal senoidal de $1 \mathrm{kHz}$ con ruido de $17 \mathrm{kHz}$ filtrada con los filtros anteriores (análisis comparativo con señal filtrada)

Fuente: los autores

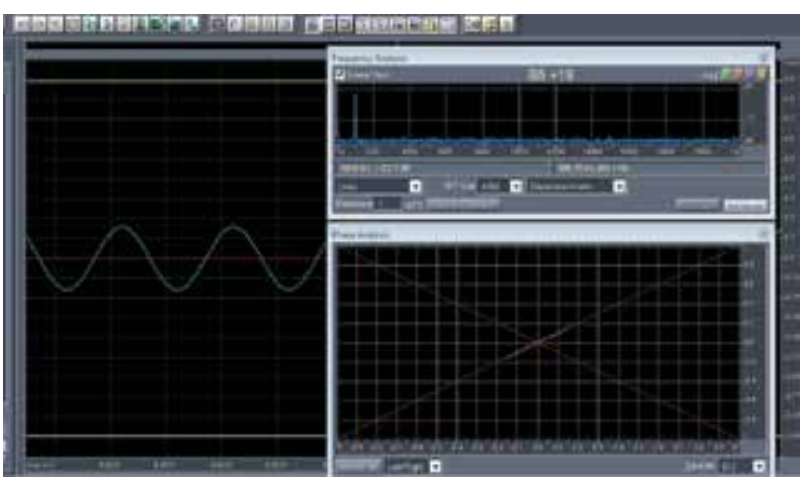

Figura 30. Análisis fasorial de la señal senoidal de $1 \mathrm{kHz}$ con ruido de $17 \mathrm{kHz}$ filtrada con los filtros anteriores (análisis comparativo con señal sin filtrar)

Fuente: los autores

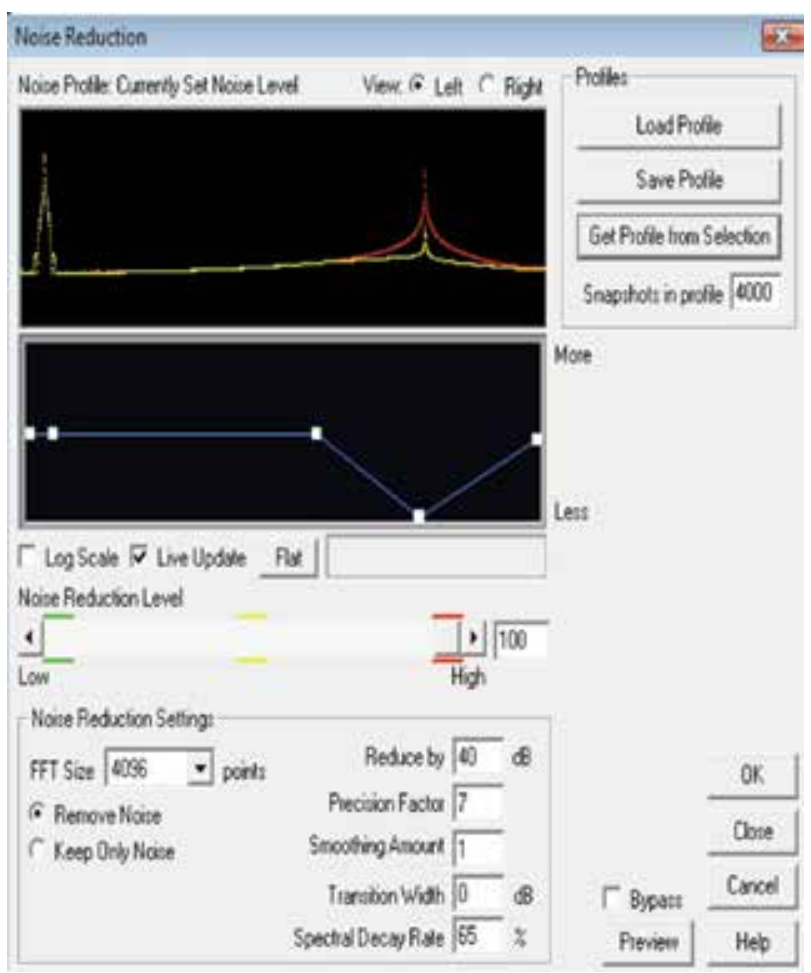

Figura 31. Análisis introduciendo algoritmos supresores de ruido para Señal senoidal de $1 \mathrm{kHz}$ con ruido de $17 \mathrm{kHz}$ filtrada con los filtros anteriores (análisis comparativo con señal filtrada) Fuente: los autores

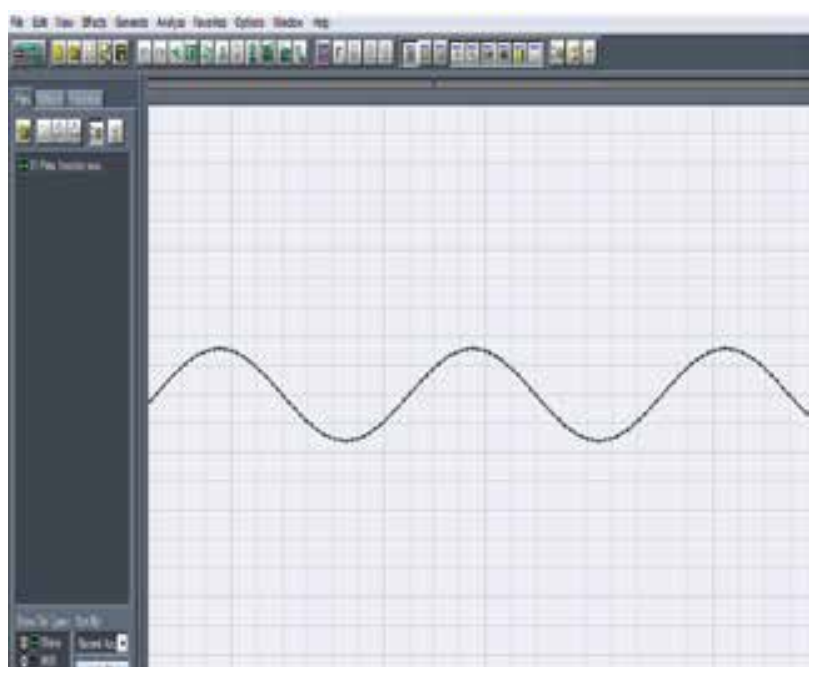

Figura 32. Señal después de pasar por software antirruido Fuente: los autores 


\section{Resultados}

\section{1. Proyección en el procesamiento de señales y conclusiones}

En el desarrollo de la presente investigación se pretende analizar el tipo de señal que presenta el oído, mediante técnicas avanzadas de procesamiento de señales, dado que con la ayuda de la instrumentación moderna se han podido percibir algunos sonidos procedentes del oído de algunos pacientes. En la actualidad el autor del presente artículo se encuentra desarrollando un proyecto de investigación encaminado al procesamiento, análisis y descripción de la señal, con el fin de buscar posibles soluciones para la determinación objetiva de esta afección, dado que en el mundo no existe un instrumento que permita objetivizar la enfermedad.

\section{Referencias}

[1] D. T. Kemp, "Stimulated acoustic emissions from within the human auditory system". J Acoust Soc Am, Vol. 64, No. 5, pp. 1386-1391, Nov., 1978.

[2] T. Gold, "Hearing II. The physical basis of the action of the cochlea”. Proc R Soc London B, Vol. 135, No. 881, pp. 492-498, Dic., 1948.

[3] D. O. Kim, "Cochlear mechanics: implications of electrophysiological and acoustical observations". Hear Res, Vol. 2, No. 3-4, pp. 297-317, Jun., 1980.

[4] J. P. Wilson, "Evidence for a cochlear origin for acoustic reemissions, threshold fine-structure and tonal tinnitus”. Hear Res, Vol. 2, No. 3-4, pp. 233-252, Jun., 1980.

[5] E. Zwicker y W. Peisl, "Cochlear preprocessing in analog models, in digital models and in human inner car". Hear Res, Vol. 44, p. 209, 1990.

[6] D. T. Kemp, S. Ryan, P. Bray, "A guide to the effective use of otoacoustic emissions". Ear Hear, Vol. 11, No. 2, pp. 93-105, Abr., 1990.

[7] B. L. Lonsbury-Martin y G. K. Martin, “The clinical utility of distorsion-product otoacustic emissions". Ear and hearing, Vol. 11, pp. 144-154, 1990.

[8] P. Bonfils, A. Uziel y R. Pujol, "Screening for auditory disfunction in infants by evoked otoacoustic emissions". Arch Otolaryngol Head Neck Surg, Vol. 114, pp. 887-890, 1988.

[9] N. Johnsen, P. Bagi, J. Parbo y C. Elberling, "Evoked otoacoustic emissions from the human ear: IV. Final results in 100 neonates". Scand Audiol, Vol. 17, No. 1., pp. 27-34, 1988.
[10] F. Rodríguez Gómez, “Aportación al conocimiento de las otoemisiones acústicas espontáneas", tesis doctoral, Facultad de Medicina de la Universidad Complutense, Madrid, España, 1989, pp. 230-241.

[11] D. T. Kemp, "Otoacoustic emissions, traveling waves and cochlear mechanisms”. Hear Res, Vol. 22, pp. 95-104, 1986.

[12] P. Bray y D. Kemp, "An advanced cochlear echo technique suitable for infant screening". British Journal of Audiology, Vol. 21, 191-204, 1987.

[13] P. J. Bray, "Click evoked emissions and the development of a clinical otoacustic hearing test instrument", tesis de grado, University of London, 1989.

[14] R. J. Nozza, "Screenig with otoacoustic emissions beyond the newborn period". Seminars in Hearing, Vol. 22, No. 4, pp. 415-425, 2001.

[15] F. P. Harris, R. Probst y R. Wenger, "Repeatibility of transiently evoked otoacoustic emissions in normally hearing humans”. Audiology, Vol. 30, pp. 135-141, 1991.

[16] M. Lonsbury-Martin, Martin. "Evoked otoacoustic emissions as objetive screeners for ototoxicity". Seminars in Hearing, Vol. 22, No. 4, pp. 377-391, 2001.

[17] D. T. Kemp, "Exploring cochear status with otoacoustic emissions. The potential for new clinical applications", en M. Robinette y Glatke (eds), Otoacoustic Emissions: Clinical Applications, 2a. ed., Nueva York: Thieme, 2002, pp. 1-47.

[18] P. Avan, "Exploration de la cochlée par les otoemissions provoquées. Interpretation physiologique des resultants". Ann Oto- Laryng, Vol. 108, pp. 135-141, 1991.

[19] M. Erminy, S. Skanavi, Th. Van Den Abbele, P. Avan y Bonfils, "Physiologie de l'audition", Encycl Méd Chir (Edit. Scientifiques et Médicales Elsevier, Paris), Otorhinolaryngologie, 20-030-A-10, pp. 1-14, 1995.

[20] A. F. Werner, Teoría y práctica de las otoemisiones acústicas, Argentina: edición del autor, 2001, pp. 93-115.

[21] Y. Guerrier y A. Uziel, Physiologie neurosensorielle en otorhinolaryngologye, París: Masson, 1985, pp. 1-211.

[22] E. Shaw, “The external ear”, en W. D. Keidel y W. D. Neff (eds.), Handbook of Sensory Physiology, Berlín: Springer-Verlag, 1974.

[23] G. Bekesy. Experiments in Hearing, Nueva York: McGraw-Hill Book, 1960.

[24] P. Avan, D. Loth, C. Menguy y M. Teyssou, "Hypothetical roles of middle ear muscles in the guinea-pig cochea". Hear Res, Vol. 9, pp. 59-69, 1992.

[25] R. Jackler y D. Brackmann. Neurotology. Ed. Mosby, 1993, pp. 1-9. 
[26] R. Nobili, F. Mammano y J. Ashmore, "How well do we understand the cochlea?". Trends Neuroscience, Vol. 21, pp. 159-167, 1998.

[27] W. E. Brownell, “Outer hair cell electromotility and otoacustic Emissions”. Ear Hear Vol. 11, No. 2, pp. 93-105, 1990.

[28] H. Spoendlin, "The organization of the cochlear receptor". Adv Otorhinolaryngol, Vol. 13, pp. 1-231, 1966.

[29] H. Spoendlin. "Innervation patterns in the Organ of Corti of the cat". Acta Otolaryngol, Vol. 67, pp. 239-254, 1969.

[30] H. Spoendlin, "Innervation densities of the cochlea". Acta Otolaryngol, Vol. 73, pp. 235-248, 1972.

[31] G. Bredberg, "Cellular pattern and nerve supply of the human organ of Corti”. Acta Otolaryngol, 1968, p. 236.

[32] J. O. Pickles, S. D. Comis y M. P, Osborne, "Cross-links between stereocilia in the guinea pig organ of Corti, and their possible relation to sensory transduction". Hear Res, Vol. 15, pp. 103-112, 1984.

[33] H. P. Zenner, G. Reuter y P. K. Plinkert, “Outer hair cells possessacetylcholine receptors and produce motile res- ponses in the organ of Corti". J. P. Wilson y D. T. Kemp (eds). Cochlear mechanisms, Nueva York, 1989, pp. 9398.

[34] I. Russell y P. M. Sellick, "Intracelular studies of hair cells in the mammaran cochlea". J Physlol, Vol. 284, pp. 261-290, 1978.

[35] J. B. Nadol, "Comparative anatomy of the cochlea and auditorynerve in mammals". Hear Res, Vol. 34, pp. 253-266, 1988.

[36] M. C. Liberman, "Physiology of cochlear efferent and afferentneurons: direct comparisons in the same animal”. Hear Res, Vol 34, pp. 179-192, 1988.

[37] A. Uziel y J. P. Pujol, "Evoked otoacoustic emissions from normal newboms and babies admitted to an intensiva care baby unit". Acta Otolaryngol, Vol. 482, pp. 85-91, 1991.

[38] A. Hudspeth, "The ionic channeis of a vertebrate hair cell”. Hear Res, Vol. 22, pp. 21-27, 1986.

[39] A. Wright, "Dimension of the cochlear stereocilia in man and the guinea-pig". Hear Res, Vol. 13, pp. 89-98, 1984. 